\title{
Increasing of filtration characteristics of ore bodies in borehole uranium mining
}

\author{
Bayan Rakishev ${ }^{1, *}$, Zhiger Kenzhetayev ${ }^{1}$, Asel Shampikova ${ }^{1}$, and Bakytzhan Toktaruly ${ }^{1}$ \\ "'SatbayevUniversity", A15P4X4, Almaty, Satbayev Str., 22, Kazakhstan
}

\begin{abstract}
There is a description of technology by borehole uranium mining in Kazakhstan. The factors which affect for reduction of filtration characteristics in productive reservoirs are studied in detail and described an effective method for increasing borehole uranium production. The processes that occur during borehole mining of uranium with the use of sulfuric acid as solvent, as well as the conditions and reasons for reducing the productivity of geotechnical wells during their operation are considered. The results of experimental work on the intensification of borehole uranium mining in complex mining and geological conditions are analyzed and discussed, comparative graphs of the content of uranium in the productive solution, the flow rate of wells, the degree of extraction and the volume of production before and after the experiments are constructed. The results of experimental work on the efficiency of borehole uranium production, the content of uranium in PS and the productivity of wells, with predominance of the chemical type of sedimentation, are positively evaluated. The optimal parameters for the intensification of borehole uranium production in complex mining and geological conditions are recommended, and method for using complex of multi-purpose chemical reagents in combination with traditional methods of well regeneration is developed.
\end{abstract}

\section{Introduction}

The Republic of Kazakhstan ranks first in terms of natural uranium production in the World and second in terms of proven reserves (after Australia), according to estimates $12 \%$ of the world's proven reserves are located on the territory of Kazakhstan, $80 \%$ of them are suitable for well mining. The technology of borehole uranium mining involves pumping out productive solutions (PS) from production wells of the production block, sorption extraction of a useful component from solutions, clarification of the masterbatch with subsequent reinforcement with concentrated sulfuric acid, and the supply of acidified leaching solution (LS) through injection wells to the ore body of the block. At the same time, dissolution is the main operation of preparing uranium ore for production, since it determines the quantity and cost of the final product. The reason of using sulfuric acid as a solvent reagent in Kazakhstan is due to the low cost, availability, and the possibility

\footnotetext{
*Corresponding author: b.rakishev@mail.ru
} 
of relatively complete conversion of uranium into solution. However, the high kinetics of the interaction of sulfuric acid with carbonate and clay minerals of ore-containing rocks causes sedimentation in the form of a geochemical barrier that prevents the dissolution process.

Hard to dissolve sediments and displaced clay particles in the productive horizon increase hydraulic resistance and form impenetrable sections of geochemical barriers that block the flow lines of solutions. As a rule, the reduction of filtration characteristics in the productive horizon leads to decrease uranium content in the PS, and a decline in the period of uninterrupted operation of wells, which slows down the process of working in the production blocks, as a result it increases consumption of sulfuric acid and other chemical reagents $[3,4]$. Wells on these blocks are often stopped for repairing and restoration work and need additional increase in the permeability of the pre-filter zone of the formation (PZF). In some cases, carrying out costly, heavy complex treatments using of drilling rigs including washing, chemical treatment, swabbing and compressor pumping do not give a positive result. There are selected and described special chemical reagents for destruction and prevention precipitation during the intensification of geotechnological processes of borehole uranium mining.

\section{$2 \mathrm{X}$-ray phase study of sedimentation}

To solve issues of increasing the filtration characteristics of host rocks, the first necessary to determine is composition of precipitation formed in the productive horizon during the sulfuric acid leaching of uranium. The study of the composition in sedimentary components allow us to determine their physical and chemical properties, and the reasons for reducing the permeability in the rock in the conditions of borehole uranium mining. Determination of physical and chemical properties of sediments is necessary for the selection of more effective methods for restoring filtration characteristics that provide an increase in productivity and the period of uninterrupted operation of geotechnical wells. To search for such methods, fragments of sedimentation are selected from the internal surfaces of submersible pumps of pumping wells from different fields of the Syrdarya and Shu-Sarysu uranium provinces. They are worked out during the sulfuric acid leaching of uranium. The dried sediments of samples № 1 are a dust- like mixture of red color, and the dried sediments of samples № 2 are white powder with beige spots and the presence of large homogeneous formations and sand.

The phase composition of colmatants was controlled by X-ray phase analysis, which was performed on an x-ray diffractometer X'pert MPD PRO (PANalytical). Studying conditions are: CuKa-radiation, Ni-filter, voltage of tube $U=30 \mathrm{kV}$, electric current of tube $I=10 \mathrm{~mA}$, rotation speed $1000 \mathrm{imp} / \mathrm{s}$, time constant $\tau=5 \mathrm{~s}, 2 \theta=10^{\circ}-90^{\circ}$. The intensity of diffraction maxima was estimated on a 100-point scale as a percentage of the highest line. The experimental data array and interplane distances are processed using the Wulf- Bragg formula. Chemical composition in the phase analysis of colmatating materials was determined in accordance with the radiographic data of the international crystallographic society. Stable reflections of x-rays on the radiograph of colmatant samples № 1 and № 2 are shown in Figure 1; they show high crystallization of precipitation-forming chemical compounds. Analysis of the values of interplane distances confirms the existence of complex ferroalumosilicates and gypsum in the composition of feldspar. The x-ray amorphous state is noticeable due to weak x-ray reflections. The results of quantitative mineralogical composition of sedimentation deposits of the Syrdarya and Chu- Sarysu depressions are shown in Table 1.

$\mathrm{X}$-ray phase analysis data shows that sedimentation from the Syrdarya and Chu- Sarysu depressions is similar in composition. Deposits of the Syrdarya depression are dominated 
by precipitation of chemical origin, such as ankerite, dolomite, gypsum $23,24,18 \%$. This is due to the increased carbonate content of the productive horizon. These precipitations are characteristic of chemical origin, formed as a result of precipitation during the interaction of carbonate minerals with sulfuric acid solutions. The deposits of the Chu-Sarysu depression are dominated by mechanical sedimentation, such as quartz, aluminum phosphate $34,22 \%$. This is due to the predominance of feldspars and clays in the productive horizon. Mechanical precipitation is formed when small fractions are dissolved, transported, and deposited in the discharge zone. The deposition of many components indicates a variety of processes occurring in ore - containing rocks during the sulfuric acid leaching of uranium.

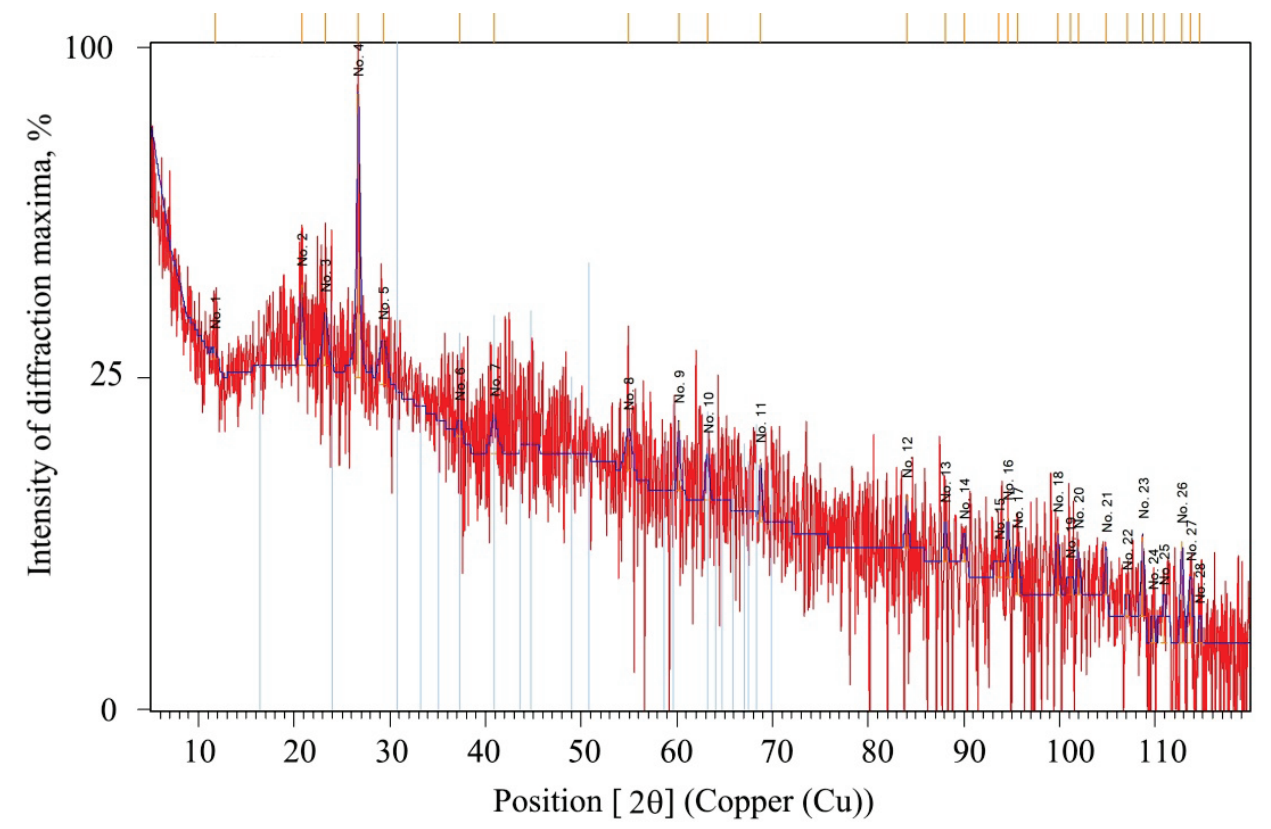

(a)

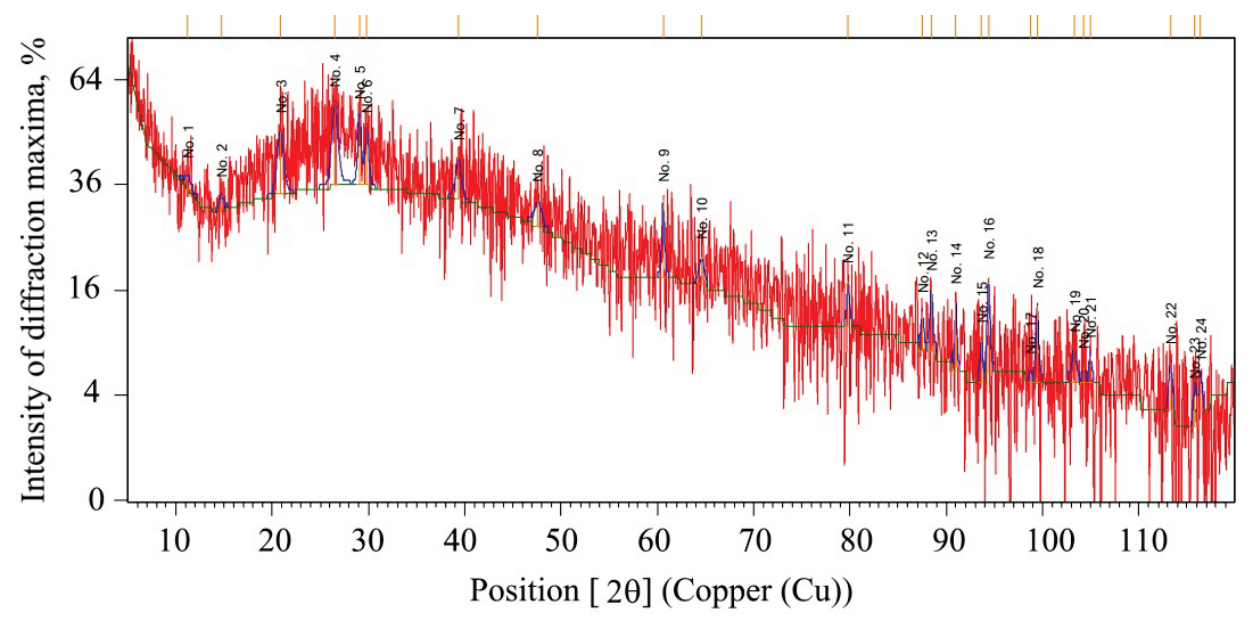

(b)

Fig. 1. Diffractogram of sedimentation from the Syrdarya (a) and Chu-Sarysu (b) depressions. 
Table 1. Mineral composition of sedimentation deposits of the Syrdarya and Chu-Sarysu depressions.

\begin{tabular}{|c|c|c|c|}
\hline $\begin{array}{c}\text { Compound } \\
\text { Name }\end{array}$ & Chemical Formula & Quant Syrdarya, [\%] & $\begin{array}{c}\text { Quant Chu-Sarysu, } \\
{[\%]}\end{array}$ \\
\hline Quartz & $\mathrm{SiO}_{2}$ & 21 & 34 \\
\hline $\begin{array}{c}\text { Aluminum } \\
\text { phosphate }(\mathrm{V})\end{array}$ & $\mathrm{Al}\left(\mathrm{PO}_{4}\right)$ & 14 & 22 \\
\hline Ankerite $\mathrm{HP}$ & $\mathrm{Ca}(\mathrm{MgFeMn})\left(\mathrm{CO}_{3}\right)_{2}$ & 23 & 25 \\
\hline Dolomite & $\mathrm{Ca} \mathrm{Mg} \mathrm{Fe}\left(\mathrm{CO}_{3}\right)_{2}$ & 24 & 12 \\
\hline Gypsum & $\mathrm{Ca} \mathrm{S} \mathrm{O} \cdot 2 \mathrm{H}_{2} \mathrm{O}$ & 18 & 17 \\
\hline
\end{tabular}

\section{Selection of chemical reagents for the intensification of borehole uranium production}

In order to select the composition of chemical reagents to improve the geotechnological processes occurring in the subsurface, the authors previously conducted research on leaching uranium from core material in tubes under laboratory conditions. According to the results of the study, the effectiveness of the selected chemical reagents in the complex for increasing the recovery of uranium in carbonate and in clay ores was confirmed. The intensification of borehole mining of uranium ores with the using complex of multi-purpose chemical reagents will increase the speed of processing of technological blocks and reduce the cost of final products. The composition of the selected chemical reagents:

Sulfamic acid- (sulfuric acid monoamide, amidoseric acid) $\mathrm{NH}_{2} \mathrm{SO}_{2} \mathrm{OH}$, mol. m. 97.098; the crystalline product is white to light gray in color, it is caked during storage. Melts at a temperature of $200-205^{\circ} \mathrm{C}$ with decomposition. It is well soluble in water, the solubility in water is significantly reduced in the presence of $70 \%$ sulfuric acid. At a temperature of $260{ }^{\circ} \mathrm{C}$, it completely decomposes into nitrogen, water and sulfur dioxide, and is non- toxic [6, 7].

Lignosulfonates are anionic surfactants. In water, they are usually in a colloidal state (the degree of hydration is $30-35 \%$ ). They slightly lower the surface tension of water, create stable emulsions and foams. Lignosulfonates are obtained as an oil- like product during the hydrolysis of wood in pulp and paper mills. Lignosulfonates are used to reduce the viscosity of clay solutions $[8,9]$.

Ammonium bifluoride $\left(\mathrm{NH}_{4} \mathrm{~F} \cdot \mathrm{HF}+\mathrm{NH}_{4} \mathrm{~F}\right)(\mathrm{BFA})$ - exists as colorless crystals, easily and quickly soluble in water, well absorbing moisture (ammonium fluoride acid can not be stored in high humidity conditions), its acidity in terms of hydrofluoric acid is $25 \%$, the density of the reagent is $1.27 \mathrm{~g} / \mathrm{cm}^{3}$. The product is toxic. For borehole mining of uranium ores successfully applied the method of acid treatment of bottom-hole zone of the wells, allowing to restore and improve its filtration characteristics, to dissolve and loosen in the bore of the tissue and increase the permeability layer zones, and hence the yield of wells $[10,11]$.

\section{Methods of conducting research and calculations on technological wells}

To improve the efficiency of uranium mining by geotechnological processes and restoring the permeability of the near-filter zone of the formation in order to increase the efficiency of uranium mining, the authors developed and tested a method for chemical treatment of wells with a special solution. This method impacts on the reservoir provides for the supply 
of complex chemical solutions to the filter zone, pressing into the productive horizon for its reaction with sedimentation, dissolution and removal of reaction products outside the well by airlift pumping. Figure 2 shows the scheme of preparation and supply of chemical reagents to the productive horizon.

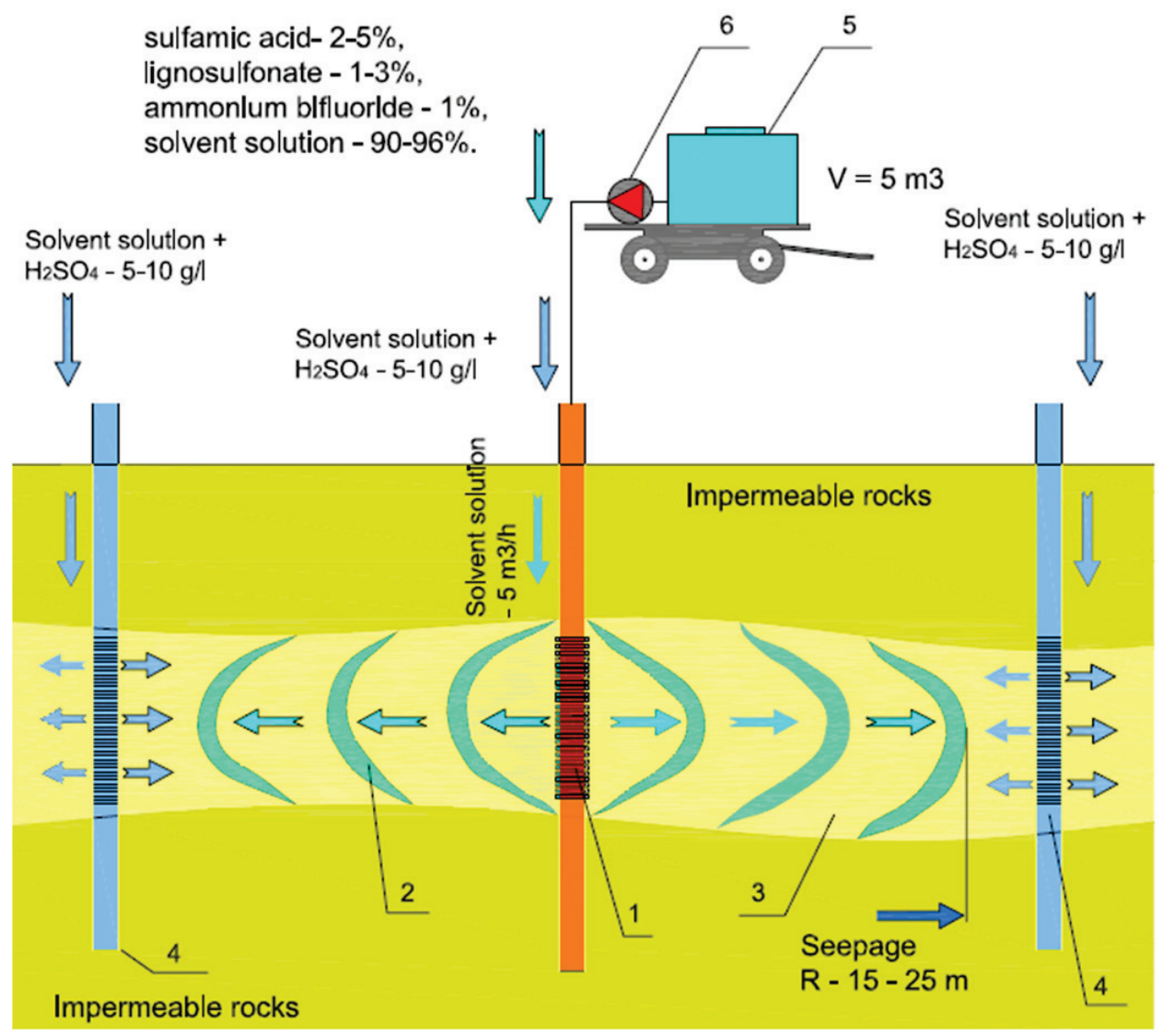

Fig. 2. Scheme of preparation of chemical reagents supply to the productive horizon: 1 - filter column of the production well; 2 - distribution of chemical reagent solutions in the productive horizon; 3 colmated productive horizon; 4 - filter column of injection wells; 5 - container for preparing chemical reagent solutions; 6 - pump for supplying chemical reagent solutions.

For correct conduct of experimental work during downhole uranium mining and compliance with the technological regime of leaching, well operation analysis, it is necessary to perform calculations of the following geotechnical parameters: the ratio of $L: S$ (Liquid:Solid), the calculated spreading radius, the average content of uranium in the PS, the degree of extraction, etc. The ratio of $L: S$ is calculated by formula (1).

$$
L: S=\frac{\sum_{i=1}^{n} \mathrm{Q}_{L S}}{M O M}
$$

$\mathrm{Q}_{L S}$ - quantity of LS (leaching solution) fed into the subsurface during time $t\left(\mathrm{~m}^{3}\right)$; $M O M$ - mining and ore mass (ton).

$$
M O M=S M \delta
$$


$S$ - leachable area (m); $M$ - effective width of the productive horizon (m); $\delta$ - volume mass of ore - containing rocks and ores $\left(\mathrm{t} / \mathrm{m}^{3}\right)$.

The calculated area of spreading of solutions from the filter, along the productive horizon is determined by the formula 1 . After using the formula 3, radius of solution spreading is calculated.

$$
S=\frac{Q-0.22}{M},
$$

where $Q$ - the volume of solutions fed into the well $\left(\mathrm{m}^{3}\right) ; 0.22$ - the average porosity coefficient of the host rocks in the productive horizon; $M$ - the effective width of the productive horizon $(\mathrm{m})$.

$$
R=\sqrt{\frac{\mathrm{S}}{\pi}} .
$$

The average content of uranium in productive solutions is determined based on the average monthly concentration in PS according to the formula 5.

$$
C_{c p}^{U}=\frac{\sum_{i=l}^{n} \mathrm{C}_{P S}^{U} Q_{P S}}{\sum_{i=1}^{n} Q_{P S}},
$$

where $C_{c p}^{U}$ - the average monthly content of uranium in PS $(\mathrm{g} / \mathrm{l}) ; Q_{P S}-$ the volume of the productive solution of the well $\left(\mathrm{m}^{3}\right)$.

Production of uranium from the subsurface of PU-defined as the amount of uranium obtained in productive solutions for a certain period of time according to the formula 6 .

$$
P_{U}=\frac{\sum_{i=1}^{n} \mathrm{C}_{P S}^{U} Q_{P S}}{1000} 0.97,
$$

where 0.97 - the accepted coefficient of recovery of uranium from the PS.

Extraction $(E)$, defined as the ratio of the amount of uranium extracted to the available reserves, is expressed as a percentage (7).

$$
E=\frac{\sum_{i=1}^{n} P_{U}}{P}
$$

$\sum_{i=1}^{n} P_{U}$ - amount of extracted uranium $(\mathrm{kg}) ; P$ - reserves of uranium $(\mathrm{kg})$.

\section{Experiments on the intensification of borehole uranium production using reagents}

Equipment for the preparation and supply of solutions of chemical reagents consists of a container and a pump, which are made of a corrosion-resistant material, due to the fact that they are in contact with LS fortified sulfuric acid. Simultaneously injected LS into wells, provided the spread of chemical reagent solutions in the productive horizon, to the effective spreading radius limited from the top and bottom by impervious rocks.

The study of the effectiveness of a solution in the complex of chemicals in terms of borehole mining of uranium at Syrdarya depression when conducting experimental work. 
Experimental work was carried out on geotechnological wells with low values of the interrepair cycle (IRC) and insufficient productivity for the PS, as well as on wells with a low content of uranium in the PS. The selected wells are characterized by a low coefficient of using; traditional methods did not give a positive result. Experimental works included the supply of specially selected chemical reagents to the productive horizon through the mouth of selected technological wells with simultaneous injection of LS into them, until the calculated radius of spreading solutions from the well filter was reached. Then, after the necessary amount of chemical reagents and LS was supplied, the production wells are compressor pumped and put into operation, while the injection wells remained in operation under LS pressure. The effectiveness of the impact of complex chemical reagents on the intensification of borehole uranium production was determined by the results of monitoring and analysis of geotechnical parameters before and after experimental work.

As can be seen from Table 2 the spreading of solutions from the well. In the first experiment the average response of LS was $3.0 \mathrm{~m}^{3} / \mathrm{h}$, with $M$ of $5.9 \mathrm{~m}$, and the length of feed of the LS 15 days, spreading from the filter was $16.3 \mathrm{~m}$. The middle upload time in the second experiment amounted to $2.1 \mathrm{~m}^{3} / \mathrm{h}, M-8.8 \mathrm{~m}$, the duration of the LS 21 days, spreading from the filter to $13.2 \mathrm{~m}$.

Table 2. Calculated data for spreading solutions from wells.

\begin{tabular}{|c|c|c|c|c|c|c|c|c|c|c|}
\hline $\begin{array}{c}\text { № } \\
\text { exper. }\end{array}$ & $\begin{array}{c}S, \\
\mathrm{M}^{2}\end{array}$ & $\begin{array}{c}M, \\
\mathrm{~m}\end{array}$ & $\begin{array}{c}M O M, \\
\mathrm{~m}^{3}\end{array}$ & $\begin{array}{c}L S, \\
\mathrm{~m}^{3}\end{array}$ & $\begin{array}{c}\mathrm{H}_{2} \mathrm{SO}_{4}, \\
\mathrm{~g} / 1\end{array}$ & $\begin{array}{c}\mathrm{H}_{2} \mathrm{SO}_{4}, \\
\mathrm{t}\end{array}$ & $\begin{array}{c}\text { Recep- } \\
\text { tion, } Q, \\
\mathrm{~m}^{3} / \mathrm{h}\end{array}$ & $\begin{array}{c}\text { Upload } \\
\text { time, } \\
\text { days }\end{array}$ & $\begin{array}{c}L: S, \\
\%\end{array}$ & $\begin{array}{c}R, \\
\mathrm{~m}\end{array}$ \\
\hline 1 & 832 & 5.9 & 4909.1 & 1080 & 4 & 4.3 & 3.0 & 15 & 13 & 16.3 \\
\hline 2 & 547 & 8.8 & 4810.9 & 1058 & 7 & 7.4 & 2.1 & 21 & 13 & 13.2 \\
\hline Total & 1379 & & 9720.0 & 2138 & - & 11.7 & 5.1 & - & 13 & - \\
\hline
\end{tabular}

\section{Discussion of the results of experimental work on wells}

The effectiveness of the impact of a complex of chemical reagents on the intensification of borehole uranium production was determined based on the results of monitoring and comparative analysis of geotechnical parameters before and after experimental work. Monitoring of geotechnical parameters of boreholes include daily testing of the PS and the determination of the uranium content, $\mathrm{pH}$ in PS, measuring the well flow rate and calculation of mined uranium and the recovery factor after the data is averaged to the monthly average on the basis of which is built graphs of the basic parameters. Figures 3-4 show graphs of geotechnological parameters of wells before and after experimental work.

Monitoring data shown in Figure 3 shows that prior to the experiments, initially the uranium content in the PS was consistently low in the range of $10-11 \mathrm{mg} / \mathrm{l}$, with low productivity values of $2.5 \mathrm{~m}^{3} / \mathrm{h}$, due to the formation of a geochemical barrier and the formation of zones impervious to LS. Low uranium content in the PS and insufficient well flow increases the duration of block development and increases the operating costs for maintenance of equipment and electricity. After conducting experimental work, and to run the well into production, you may notice a significant increase in the uranium content in PS in June - July, from 12.4 to $20.0 \mathrm{mg} / \mathrm{l}$, and the simultaneous reconstruction of flow rates from 2.5 up to $5.5 \mathrm{~m}^{3} / \mathrm{h}$. This is caused by increased permeability of the productive strata of the well and the destruction of geochemical barrier in the formation. The subsequent decrease in the uranium content to the initial values of $11 \mathrm{mg} / 1$ is associated with the development of reserves and leaching of uranium. 


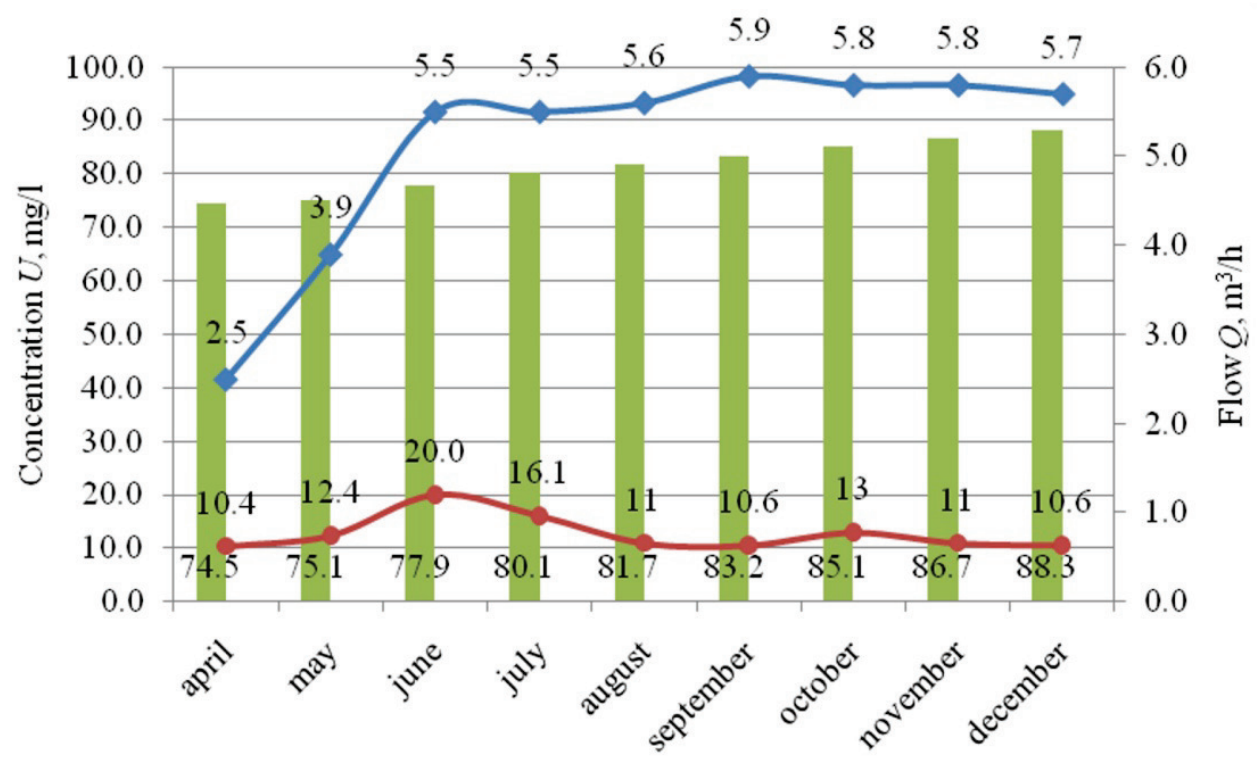

Extraction, \% $\rightarrow$ Concentration $U, \mathrm{mg} / \mathrm{dm}^{3} \leadsto$ Flow $Q, \mathrm{~m}^{3} / \mathrm{h}$

Fig. 3. Geotechnical parameters of well 1 before and after experimental work.

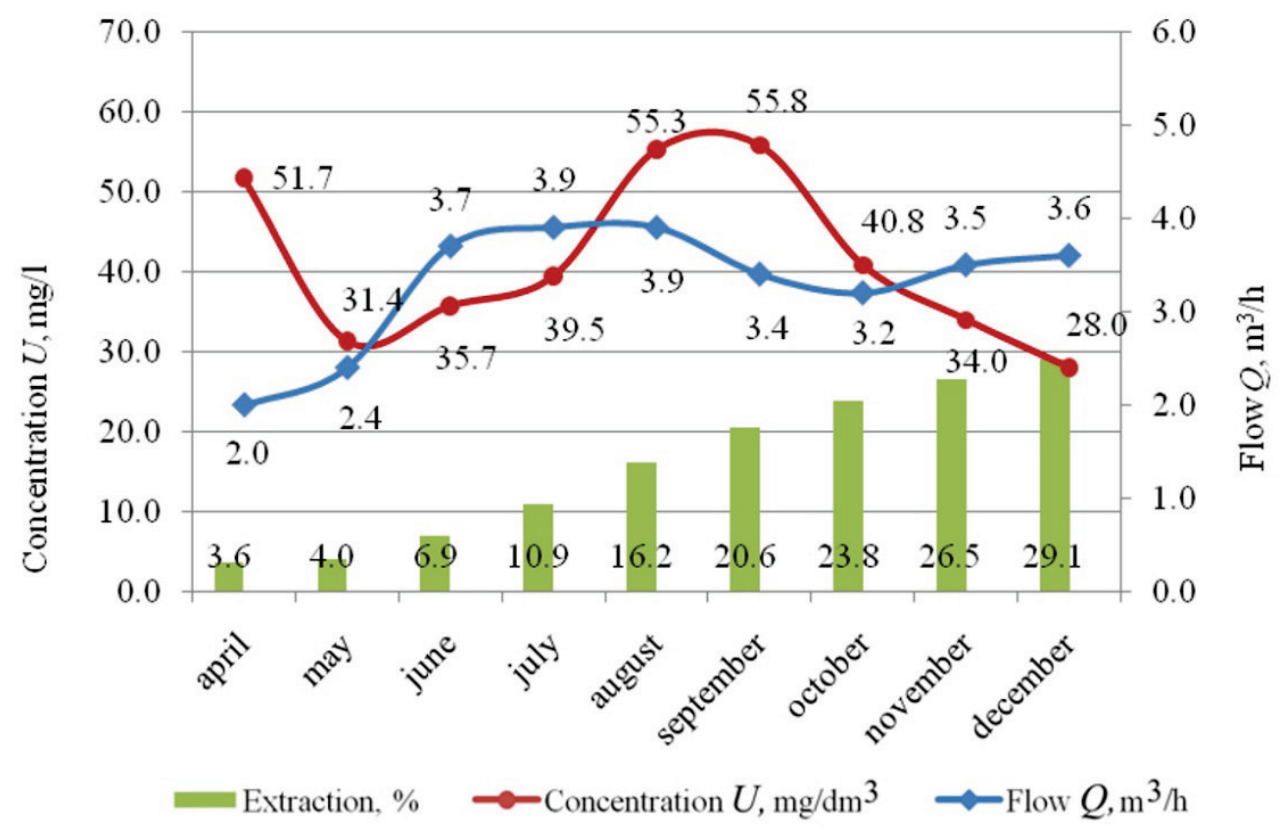

Fig. 4. Geotechnical parameters of well 2 before and after experimental work.

The results of monitoring the geotechnological parameters of well 2 shown in figure 4 show that before the experiments, initially the content of uranium in the PS was sharply reduced from 51.7 to $31.4 \mathrm{mg} / \mathrm{l}$, with low productivity values of $2.01-2.47 \mathrm{~m}^{3} / \mathrm{h}$, due to the formation of a geochemical barrier and the formation of zones impervious to LS in the productive horizon. After conducting experimental work, and to run the well into 
production, you may notice a slight increase in the uranium content in PS in June - July months, from 31.4 to $39.5 \mathrm{mg} / \mathrm{l}$, however, in this period of time the production rate significantly increased from average of 2.47 to $3.97 \mathrm{~m}^{3} / \mathrm{h}$. this is caused by increased permeability of the productive horizon and the destruction of geochemical barriers. The subsequent increase in the uranium content from 39.5 to $56.6 \mathrm{mg} / \mathrm{l}$ is associated with the arrival of a front of solutions with an increased content of uranium moving from the injection wells of the process cell. The average increase in the extraction of uranium from the subsoil in the period March-May was $1.68 \%$, and in the period June - December after the experiment was $3.69 \%$.

According to the analysis of experimental work on the wells Syrdarya depression we observed a significant increase in the concentration of uranium in the PS and increasing the flow rate of production wells, which increases the coefficient of extraction of uranium from the subsurface. The use of selected chemical reagents for the purpose of intensifying borehole uranium production had a positive impact on the dynamics of uranium production as a result of restoration of filtration characteristics and effective destruction of the geochemical barrier and subsequent prevention of sedimentation in a porous environment.

\section{Conclusions}

X-ray phase studies of the composition of precipitation of sulfuric acid leaching in laboratory conditions, determination of quantitative and qualitative characteristics of precipitation and allowed to establish the reasons for the decrease in filtration characteristics of ores and host rocks. As a result of studying the applied methods of well regeneration and the selection of chemical reagents that increase the geotechnical characteristics of ores, a method for intensifying borehole uranium production in difficult mining and geological conditions was developed. Based on the conducted experimental studies, it is possible to note the positive effect of chemical reagents at the stage of active leaching of uranium, as well as during acidification in areas with increased carbonate content and clay content of the productive horizon. One of the conditions for effective exposure to chemical reagents is the localization of supply and concentration of work on individual sites and cells, with a low filtration coefficient $<1-2$. As well as the integrity of geotechnical cells for the total coverage of the mining and ore mass, and the supply of reagents to pumping and injection wells. As a result of exposure to chemical reagents, the formed impenetrable geochemical barriers are actively destroyed and further sedimentation in the productive horizon is prevented for a long time. In areas with favorable filtration characteristics, the consumption of chemical reagents increases and the results decrease as a result of an increase in the spreading area. Intensification of borehole uranium mining in complex mining and geological conditions should be carried out using a complex of multipurpose chemical reagents, depending on the composition of ore-containing rocks $[11,12]$. The supply of effective concentrations of chemical reagents to the leaching solution in combination with traditional well regeneration methods intensifies the process of leaching uranium.

\section{References}

1. Rakishev, B. R., Bondarenko, V. I., Matev, M. M., Kenzhetaev, Z. S. (2019). Influence of chemical reagent complex on intensification of uranium well extraction. Naukovyi Visnyk Natsionalnoho Hirnychoho Universytetu, (6), 25 - 30

2. Matev, M. M., Rakishev, B. R., Kenzhetaev, G. S. (2017). The impact of ammonium bifluoride complex on colmataging formations during the process ofin situ uranium 
leaching. International journal of advanced research, (5), 147 - 154

3. Rakishev, B. R., Mataev, M. M., Kenzhetaev, J. S. (2019). The study of the mineralogical composition of sedimentation in the conditions of downhole uranium mining. Mining Information and Analytical Bulletin, (7), 123 - 131

4. Yusupov, H. A., Dzhakupov, D. A., Bashilova, E. S. (2018). Improving the efficiency of mining complex hydrogenic uranium deposits using hydrogen peroxide. Mining Journal of Kazakhstan, (2), 18 - 21

5. Yusupov, H. A., Aliev, S. B., Dzhakupov, D. A., Elzhanov, E. A. (2017). The use of ammonium bifluoride for chemical treatment of wells during underground leaching of uranium. Mining Journal, (4), 57 - 60

6. Y. M. Khawassek, M. H. Taha, A. A. Eliwa. (2016). Kinetics of Leaching Process Using Sulfuric Acid for Sella Uranium Ore Material, South Eastern Desert. (Egypt International Journal of Nuclear Energy Science and Engineering, (6), 62 - 73

7. Gorbatenko, O. A. (2017). Repair and restoration work on geotechnological wells of PSV uranium enterprises: textbook. allowance; under the editorship of Yu.V. Demekhova. Almaty: NAC Kazatomprom

8. Molchanov, A. A., Demekhov, Yu. V. (2014). Improving the efficiency of uranium mining from hydrogen-type deposits developed by the method of underground borehole leaching of the Republic of Kazakhstan (by the example of the eastern Mynkuduk deposit). Actual problems of the uranium industry VII international. Conf: Sat scientific works

9. J. Chen, Y. Zhao, Q. Song, Z. Zhou, S. Yang. (2018). Exploration and mining evaluation system and price prediction of uranium resources. Mining of Mineral Deposits, 12(1), $85-94$

10. Nikitina, Yu. G., Poyezzhayev, I. P., Myrzabek, G. A. (2019). Improvement of opening schemes of wellfilds to optimize the cost of mining uranium. Gornyi Vestnik Uzbekistana, (1), 6 - 11

11. Alikulov, S. S., Sobirov, Z., Khaidarova, M. E. (2018). Research and implementation of the methods of limiting the difflnce of product solutions and the intensifiation of underground leaching workflws. Gornyi Zhurnal, (3), 100 - 106

12. Uralbekov, B., Burkitbayev, M., Satybaldiev, B. (2015). Evaluation of the effctiveness of the fitration leaching for uranium recovery from uranium ore. Chemical Bulletin of Kazakh National University, (3), 22 - 27

13. Rakishev, B. R. (2019). Mining and metallurgical complex and the development of civilization. Mountain Journal, (9), 33 - 37

14. Rysbekov, K., Huayang, D., Kalybekov, T. (2019). Application features of the surface laser scanning technology when solving the main tasks of surveying support for reclamation. Mining of mineral deposits, 13(3), $40-48$.

15. P. Lachab, M. Cathelineaua, M. Brouandc, N. Fiet. (2015). In-situ isotopic and chemical study of pyrite from Chu-Sarysu (Kazakhstan) roll-front uranium deposit. Procedia Earth and Planetary Science, (13), 207 - 210 